\title{
照 Springer
}

Draft Manuscript for Review

\section{Follow-up guidance for metal-on-metal hip replacement patients should be updated}

\begin{tabular}{|r|l|}
\hline Journal: & International Orthopaedics \\
\hline Manuscript ID: & Draft \\
\hline Danuscript Type: & Letter to the Editor \\
\hline Complete List of Authors: & Math \\
\hline & $\begin{array}{l}\text { Matharu, Gulraj; Nuffield Orthopaedic Centre, Nuffield Department of } \\
\text { Orthopaedics, Rheumatology and Musculoskeletal Sciences } \\
\text { Orthopaedics, Rheumatology and Musculoskeletal Sciences } \\
\text { Murray, David; Nuffield Orthopaedic Centre, Nuffield Department of } \\
\text { Orthopaedics, Rheumatology and Musculoskeletal Sciences } \\
\text { Pandit, Hemant; Nuffield Orthopaedic Centre, Nuffield Department of } \\
\text { Orthopaedics, Rheumatology and Musculoskeletal Sciences }\end{array}$ \\
\hline Keywords: & metal-on-metal, follow-up, hip replacement \\
\hline \multicolumn{2}{|c}{} \\
\hline
\end{tabular}




\section{Follow-up guidance for metal-on-metal hip replacement patients should be updated}

We read the recent paper by Reito et al. with great interest [1]. In an attempt to identify patients with adverse reactions to metal debris (ARMD) early, regulatory authorities have published follow-up guidance for MoM hip patients (hip resurfacing (HR) and total hip replacement (THR)) [2,3]. Decisions regarding follow-up frequency requires well designed longitudinal cohort studies with patients undergoing repeated assessments, however such studies are lacking. Whilst the study from Reito et al. reports changes occurring in blood metal ion concentrations at short-term follow-up (mean one-year between blood sampling), the work provides important information which can be used to guide patient follow-up.

The main study findings in 254 patients with high-risk implants (Articular Surface Replacement (ASR)) were that repeat whole blood metal ion concentrations remained below a previously published threshold [4] in most unilateral HR patients, but not in THR patients [1]. In THR patients, 50\% had initial blood metal ion levels exceeding this threshold, with $32 \%$ of those with normal initial cobalt concentrations developing levels above the threshold on repeat testing [1]. The findings suggest that repeat blood metal ion sampling may be useful annually for high-risk large-diameter THR devices, but not for high-risk HR devices. A previous longitudinal study of 205 unilateral HRs (predominantly ASRs) repeating blood sampling at 27 months similarly demonstrated no significant difference in cobalt concentrations since implantation [5]. 
One study limitation recognised by Reito et al. was that their findings were only applicable to ASR hips. This is important to be aware of given blood metal ions can significantly decrease at ten-years in HRs with established track-records [6]. In addition, although the blood metal ion thresholds used were developed in a previous study [4], they were devised using HR patients. Therefore the thresholds cannot be assumed to apply in THRs, especially since metal ion generation and corrosion can occur at modular junctions as well as the bearing surface. This limitation must be considered when interpreting their results. Furthermore, although the authors did carry out cross-sectional imaging and collected functional outcomes (Oxford Hip Score and Harris Hip Score), none of this important data was presented.

It is becoming clear that current follow-up guidance is no longer evidence based $[2,3]$. European guidance recommends annual blood metal ion sampling for all HR devices [3], whilst the United Kingdom recommends repeat blood sampling within three-months for patients with high initial levels [2]. Even with high-risk HR devices, evidence suggests patients with low initial blood metal ion concentrations do not require annual testing unless they become symptomatic [1,5]. Follow-up guidance from regulatory authorities therefore requires updating in line with the latest evidence. This has potentially massive financial savings (blood metal ion sampling at our hospital costs $£ 50$ or 63 Euros) and more effective use of clinical resources. It is recommended that well designed longitudinal studies are undertaken in patients with different MoM hip implants to further refine follow-up guidance so we can deliver both clinically and cost-effective patient care. 


\section{References}

1. Reito A, Moilanen T, Puolakka T, Pajamäki J, Eskelinen A (2014) Repeated metal ion measurements in patients with high risk metal-on-metal hip replacement. Int Orthop 38:1353-1361.

2. Medical and Healthcare products Regulatory Agency (MHRA) (2012). Medical Device Alert: all metal-on-metal (MoM) hip replacements. MDA/2012/036. http://www.mhra.gov.uk/. (last accessed 14 November 2014).

3. European Federation of National Associations of Orthopaedics and Traumatology (2012). Consensus statement "Current Evidence on the Management of Metal-on-Metal Bearings.” http://www.efort.org/communications/pdf/2012_05_10_MoM_Consensus_statement.pdf (last accessed 14 November 2014).

4. Van Der Straeten C, Grammatopoulos G, Gill HS, Calistri A, Campbell P, De Smet KA (2013) The 2012 Otto Aufranc Award: The interpretation of metal ion levels in unilateral and bilateral hip resurfacing. Clin Orthop Relat Res 471:377-385.

5. Langton DJ, Sidaginamale RP, Joyce TJ, Natu S, Blain P, Jefferson RD, et al (2013) The clinical implications of elevated blood metal ion concentrations in asymptomatic patients with MoM hip resurfacings: a cohort study. BMJ Open 3:e001541.

6. Van Der Straeten C, Van Quickenborne D, De Roest B, Calistri A, Victor J, De Smet K (2013) Metal ion levels from well-functioning Birmingham Hip Resurfacings decline significantly at ten years. Bone Joint J 95:1332-1338. 